\title{
EL RETABLO DE LOS FRANCHI: HISTORIA DE UNA DISPUTA EN EL CONVENTO DE SAN JOSÉ DE LA OROTAVA EN 1730
}

\author{
Jesús Rodríguez Bravo*
}

\section{RESUMEN}

El convento de San José de La Orotava fue una de las fundaciones femeninas más importantes de la orden franciscana en Canarias. Su enorme desarrollo arquitectónico, la variedad y singularidad de las obras de arte que albergaba y su ubicación en el centro urbano lo convirtieron en un hito artístico especialmente interesante. Entre finales del siglo XVII y comienzos del xviıI sufrió una de las intervenciones más destacadas en su larga historia, que supuso la práctica reconstrucción de su iglesia. Al finalizar esta obra, los dueños de los retablos se vieron obligados a adecentarlos. Todos lo hicieron sin problema, excepto la familia Franchi. En este artículo repasamos la disputa que este hecho suscitó entre las monjas y la histórica familia a cuenta de su retablo.

Palabras clave: Franchi, Orotava, retablo, convento de San José, escultura.

\section{THE ALTARPIECE OF THE FRANCHI FAMILY: HISTORY OF A DISPUTE AT THE CONVENT OF SAN JOSÉ OF LA OROTAVA IN 1730}

\section{Abstract}

The convent of San José in La Orotava was one of the most important female foundations of the Franciscan order in the Canary Islands. Its enormous architectural development, the variety and uniqueness of the works of art and its location in the city centre made it an specially interesting artistic landmark. Between the end of the 17th century and the beginning of the 18th century, it had one of the most outstanding interventions in its long history, which involved the reconstruction of its church. When this work was completed, the owners of the altarpieces were forced to adapt them. Everyone did it without any problem, except the Franchi family. In this article we review the dispute that this fact raised between the nuns and the historical family on account of their altarpiece.

KeYwords: Franchi, Orotava, altarpiece, convent of San José, sculpture. 


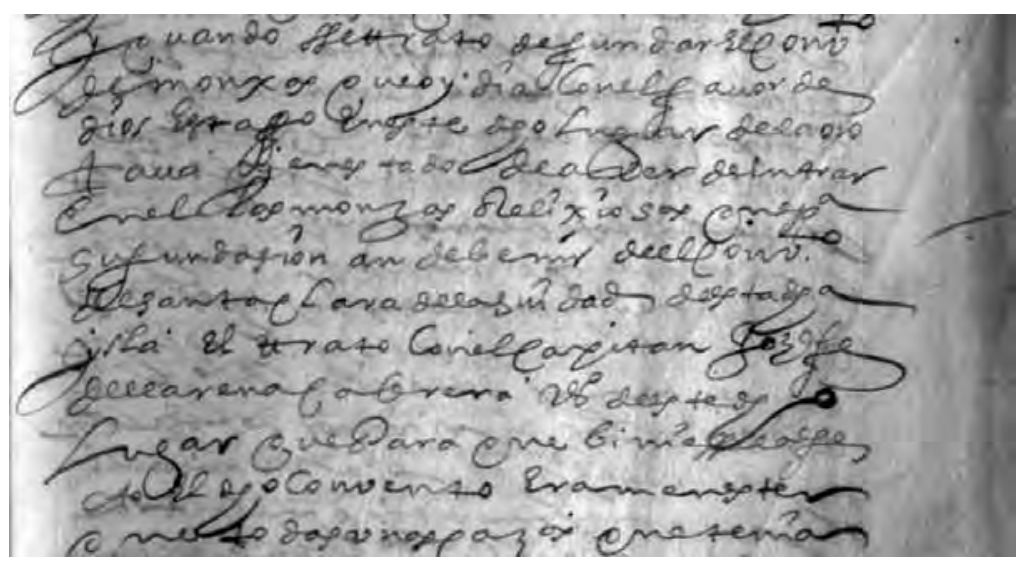

Fig. 1. Detalle del protocolo de fundación del convento de San José. Copia del siglo XviII.

\section{APUNTES SOBRE EL CONVENTO DE SAN JOSÉ}

A finales del siglo Xvi, el matrimonio formado por el coronel José de Llarena e Isabel Ana Calderón abrigó la idea de fundar un convento de monjas clarisas en el lugar que ocupaba su casa en La Orotava. Como dice José de Viera y Clavijo, lo hicieron con la esperanza de que «hubiese un convento» donde colocar y dotar a las hijas "de los vecinos de aquel pueblo», donde había "muchos con haciendas e hijas». Su deseo se hizo realidad relativamente pronto y en 1597 obtuvieron licencia real, aunque la fundación no fue verificada hasta 1601, en cuyo mes de enero se establecieron en las casas de los patronos sus hijas Catalina de San Francisco Llarena como abadesa y María del Cristo Llarena, llegadas desde el monasterio de Santa Clara de La Laguna ${ }^{1}$. Desde su establecimiento, las monjas debieron obediencia al convento franciscano de San Lorenzo, primera fundación monástica aparecida en La Orotava, y a lo largo del tiempo el convento de San José llegó a contar con setenta religiosas y unas rentas que ascendían a 50000 ducados $^{2}$ (fig. 1).

* Licenciado en Historia del Arte. Profesor de la Consejería de Educación, Universidades, Cultura y Deportes del Gobierno de Canarias. Email: jesusrodriguezbravo@gmail. com. ORCID: 0000-0003-0836-6907. Academia.edu: https://independent.academia.edu/ Jes\%C3\%BAsRodr\%C3\%ADguezBravo.

${ }^{1}$ Y con ellas llegaron Ana de San José; las hermanas Jacobina de Santa Isabel Lutzardo e Isabel de San Leandro; Luisa de la Cruz; y Francisca Esteban Grimaldo.

${ }^{2}$ Véanse Hernández González, Manuel (2004): Los conventos de La Orotava. Santa Cruz de Tenerife: Ediciones Idea; y Viera y Clavijo, José de (2016): Historia de Canarias (edición, introducción y notas de Manuel de Paz Sánchez), cuatro volúmenes. Santa Cruz de Tenerife: Ediciones Idea. 


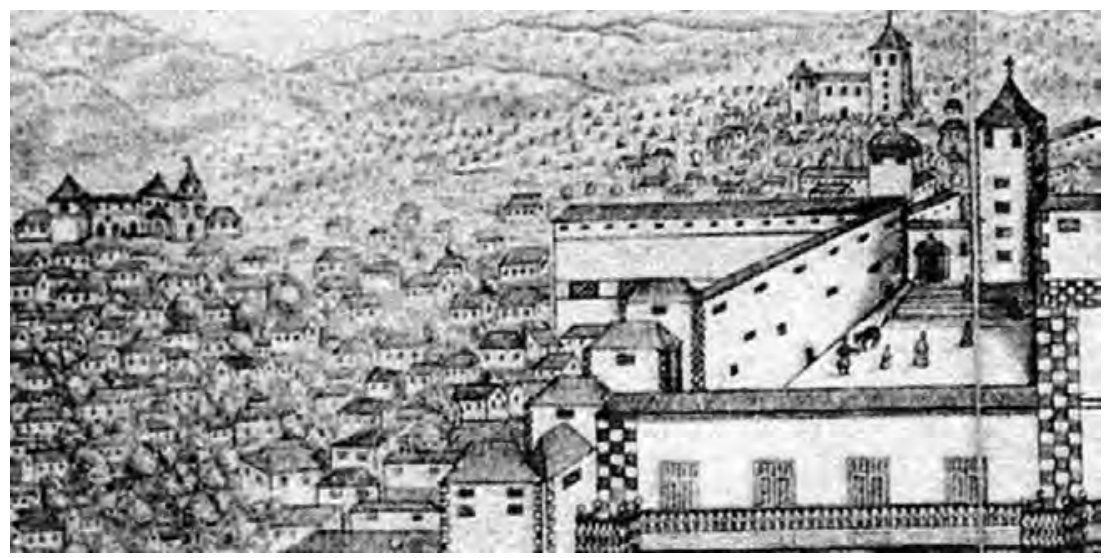

Fig. 2. Detalle del grabado de Cattoir.

Las casas de los fundadores estaban situadas en el mismo centro de la población, por esas fechas aún en fuerte y continuo desarrollo, pero claramente definido planimétricamente. La enorme manzana sobre la que con el tiempo se extendería estaba prácticamente acotada desde finales del siglo xvi. Esta idea se desprende de la documentación que sobre las construcciones previas a la existencia del monasterio se conserva en protocolos posteriores. Por ejemplo, si nos remitimos al famoso plano conservado en el Archivo General de Simancas podemos apreciar muy bien el desarrollo urbano de la zona y, aunque es más tardío, en él se ven los límites físicos (la calle de San Francisco al oeste, el barranco de Araujo al este, el barrio del Farrobo al sur y la calle Viera al norte) del espacio que llegaría a ocupar el edificio.

El centro urbano, por lo tanto, era un espacio delimitado y pequeńo, en el que se habían concentrado bastantes vecinos, entendido esto como grandes propietarios con grandes casas y pequeñas viviendas que de alguna manera se relacionaban con ellas. Esta concentración podemos observarla claramente en un famoso grabado posterior, obra de Simon Cattoir a partir de dibujos de C. de Freudenberg, y que representa a una población escalonada, formada por numerosas viviendas y destacados hitos arquitectónicos, todos en torno al primitivo templo de La Concepción (fig. 2).

En ese contexto, la manzana que terminaría ocupando el convento era un conjunto de construcciones pequeñas, con huertas y callejones interiores que serían ocupados sucesivamente, en un período de más de doscientos setenta años.

La construcción del edificio y su incesante ampliación y mejora dieron lugar a un complejo de casas unidas y perimetradas por el muro conventual, que ocupaba unos 8000 metros cuadrados, lo que convertía al monasterio en uno de los más grandes de Canarias (fig. 3). En ese largo y constante proceso intervinieron distintos artistas que dieron forma a las aspiraciones de los fundadores y de sus sucesores, pero también de las monjas. Algunas de estas intervenciones podrían calificarse 


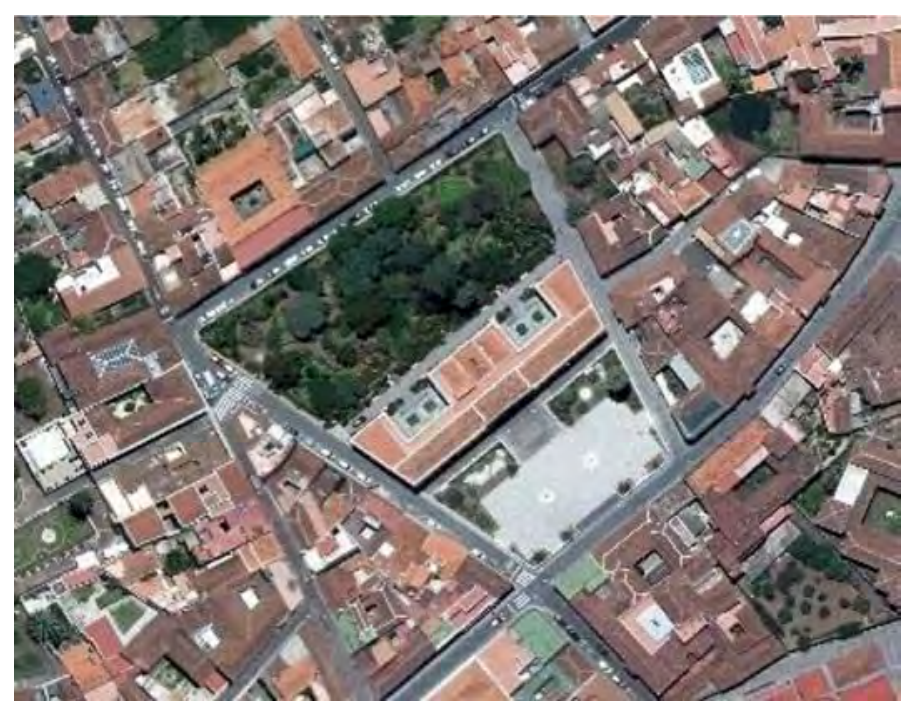

Fig. 3. Manzana trapezoidal que originariamente ocupaba el convento de San José. Fuente: GRAFCAN 2018.

casi como reconstrucciones, como la que alrededor de 1643 llevó a cabo el maestro de albañilería Mateo González, que se encargó de unas obras que supusieron un gasto considerable de dinero y que ascendieron a más de cinco mil ducados ${ }^{3}$. Y en la segunda mitad de 1649 se intervino en el coro, modificándolo completamente y mejorando también el corredor y construyendo un nuevo ajimez ${ }^{4}$. La financiación y los gastos de la obra dan idea de su envergadura ya «que se gastaron en jornales y comida de quatrosientos y sesenta y nuebe peones que andubieron desde primero de mayo hasta veinte y ocho de agosto con la obra del choro, mirador, locutorio y lo demás que se hizo en el convento" "5 que incluyeron 3500 ladrillos y 1855 reales que se dieron a José Piñero, que intervino junto con Gonzalo Díaz y con el carpintero Salvador Rodríguez Quixada. Esta obra supuso la reconstrucción de la iglesia, que se «deshizo y volvió a hacer». Las monjas contribuyeron económicamente a la obra, dentro de su gasto habitual, pero también lo hicieron particulares, como Cristóbal Delgado, que aportó 6000 reales. La reedificación continuó, al menos, hasta $1654^{6}$.

${ }^{3}$ Archivo Histórico Provincial de Tenerife (en adelante AHPT), Conventos, 2936. Libro de gasto. Gastos referidos de 1643 a 1644.

${ }^{4}$ AHPT, Conventos, 2936. Libro de gasto. Gastos referidos de 1649 a 1650.

5 AHPT, Conventos, 2936. Libro de gasto. Suma de gastos de 1649.

6 AHPT, Conventos, 2936. Libro de gasto. Suma de gastos de octubre de 1653 a febrero de 1654 . 
Al comenzar el siglo xviII, se continuaba interviniendo en la enorme manzana, como cuando en agosto de 1713 se gastan más de 28000 reales gracias a la redención de diferentes tributos, pensiones e impuestos que sobre unas viñas y tierra calma tenían en el pago de la Montañeta y que habían otorgado en escritura a favor de Diego José de Tolosa dos años antes y que se utilizaron "principalmente para la fábrica del quarto nuevo y otras obras nesesarias y presisas que sean hecho y estan hasiendo en este dicho convento»?.

En los primeros treinta años del nuevo siglo, se debió realizar una nueva actuación en la iglesia, tal y como veremos, porque es en 1730 cuando sucede el hecho que estudiamos en este artículo y que acontecerá tras haber reedificado parte del templo. En los años posteriores las rentas del convento y las obras no cesarán. En el caso de las primeras, irán menguando poco a poco conforme se acerque el siglo XIX y las segundas afectarán a lugares concretos del edificio, sin modificar demasiado el aspecto que ya tendría a mediados del XviII. La mayor parte del dinero que entró en los años treinta del setecientos provenía de dotes. Por ejemplo, de los 36326 reales que había en el convento entre 1734 y 1737, casi el 85 por ciento tenía ese origen $^{8}$. A su vez, de ese dinero se habían gastado en esos cuatro años 21238 reales, es decir, casi un 59 por ciento. Y de esa cantidad, 18000 se habían destinado a comprar tierras y 2500 «para fabricar». En ese mismo período trabajarán en el monasterio "el maestro Miguel Pico» y su hijo, varios carpinteros, el maestro Juan García y varios peones ${ }^{9}$. Sus salarios variarán en función de su categoría, desde los cinco reales por día del primero, tres para los carpinteros o tres de plata el maestro García hasta los dos reales por día de los peones ${ }^{10}$. La obra tuvo que ser importante, pues, entre otras muchas cosas, se compraron treinta y seis vigas, siete madres, diez ajimeces o catorce pilares y duró casi dos meses. Gracias a los datos obtenidos de la documentación podemos afirmar que se trató de una de las crujías del claustro. No vamos a entrar en otras intervenciones llevadas a cabo hasta 1798 o en artistas que se vieron vinculados al convento, como Amaro Jordán, Gaspar de Quevedo o Feliciano de Abreu, pero sí diremos que todavía a mediados del siglo xviII continuaron comprando casas para unir a la clausura, lo que suponía «la fabrica de los muros de la division ${ }^{11}$. Incluso en 1761 adquirieron la casa de Cecilia Ome, situada "por encima de la Capilla mayor del convento» ${ }^{12}$.

${ }^{7}$ AHPT, Conventos, 2929. Libro de escrituras de la cofradia del santo nombre de Jesús, f. 54 y ss.

8 AHPT, Conventos 2930. Libro de arca, 1737-1798. De dos celdas que se vendieron en esas fechas se obtuvieron 1600 reales, a los que había que sumar 3800 de otros ingresos.

${ }^{9}$ El maestro Pico trabajará también en la ermita de La Cruz Santa, en Los Realejos.

${ }_{10}$ AHPT, Conventos, 2933. Quenta y razon del recibo y gasto, que ha avido en la fabrica de la Cruxia... 1734-1735.

${ }^{11}$ AHPT, Conventos 2930. Libro de arca, 1737-1798. Anotación hecha el 25 de octubre de 1741 .

12 AHPT, Conventos 2930. Libro de arca, 1737-1798. Anotación hecha el 1 y el 5 de noviembre de 1761. Pagan seis pesos por la labor de apreciar la casa. 


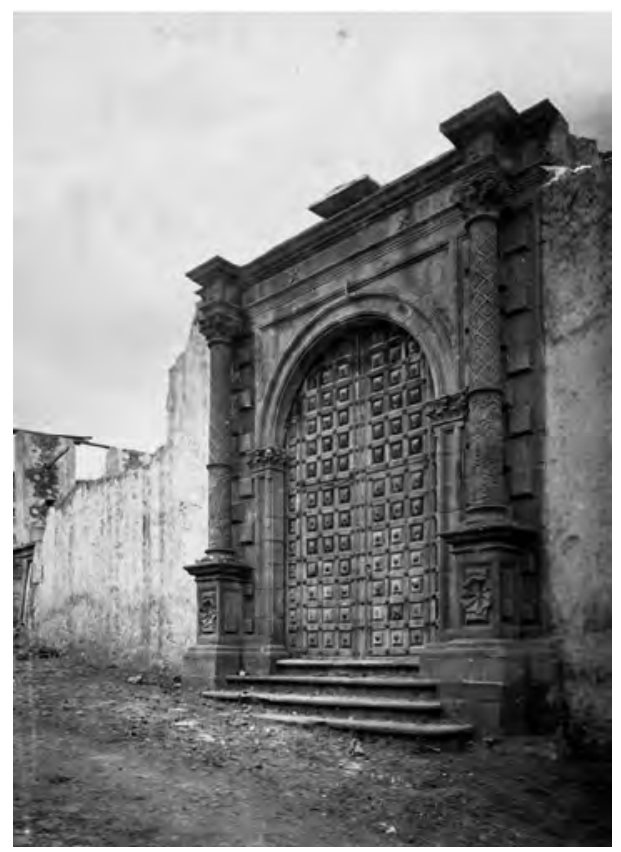

Fig. 4. Portada de la iglesia del convento de San José en el momento de su derribo. Lady Annie Brassey Photograph Collection, The Huntington Library.

Con los años, los gastos irán superando a los ingresos, lo que, unido a la bajada en el número de religiosas y al cambio en las mentalidades, desembocará en su cierre. Si bien es cierto que éste no se producirá hasta 1869 gracias a una prerrogativa por la que se les permitió continuar tras la desamortización. Pero la llegada de la etapa revolucionaria en torno a esa fecha terminará por hacerlo desaparecer y con él su rico patrimonio (fig. 4).

\section{LA DISPUTA POR EL RETABLO}

Los hechos que nos ocupan comenzaron en los primeros meses de $1730 \mathrm{y}$ son una mezcla de renovación, desidia y disputas familiares, a cuenta de un retablo que la familia Franchi tenía en la iglesia del convento ${ }^{13}$. En el primer trimestre de

13 Archivo Histórico Nacional (en adelante AHN), 1798-1. Autos del Monasterio de Santa Clara contra los herederos de Don Juan Francisco de Franquis y Doña Magdalena Benitez sobre un altar. Documentos fechados entre 1730 y 1731. 
ese año, la abadesa María Antonia de san Jerónimo Valcárcel requirió a los patronos de cada altar del templo para que los «compongan y aseen» según era su obligación, ya que el visitador Juan Mireles no los había encontrado debidamente atendidos. El requerimiento tuvo su efecto y todos los afectados cumplieron sus obligaciones. Todos excepto los herederos de Juan Francisco de Franchi y Magdalena Benítez de Lugo, que tenían «uno arriva del Púlpito de dicha Yglecia en el qual nada se a hecho». Pasado un tiempo prudencial y ante esta dejadez y abandono, las monjas decidieron acudir al vicario Martín Bucaille y el 26 de mayo el notario apostólico Andrés Alfonso comenzó a comunicar los autos a los herederos.

El fundador, Juan Francisco de Franchi Interián, había nacido en La Orotava en 1630 y heredado el mayorazgo de su histórica familia ${ }^{14}$. Estaba casado con Magdalena Benítez de Lugo y Vergara, que era hermana del primer marqués de Celada, con la que tuvo ocho hijos. Los autos del notario fueron notificados a tres de ellos, ya que, de los restantes, uno era fraile franciscano y otro dominico, dos eran mujeres, una de ellas monja en el convento de San Nicolás de la misma población, y el último pero primogénito de la familia había fallecido en 1713 .

En primer lugar se comunicó la obligación que tenían de cuidar el retablo a Juan Francisco de Franchi, caballero de la orden de Calatrava, y a su hermano Carlos, herederos de los fundadores. El primero tenía 78 años y morirá siete años después de estos hechos; el segundo contaba con 62. En segundo lugar el notario se lo comunicó a Juan Domingo de Franchi, que era nieto de los fundadores y sobrino de los anteriores, además de ser el heredero principal de la casa Franchi, que expresó que a pesar «de no tener obligacion a contribuir para los aseos y reparos de el altar que se refiere se allana a cuidar de haser se componga y repare de todo». Y por último le notificó los autos a Cristóbal de Franchi, quien pidió disponer de los mismos para poder alegar justicia. Cristóbal de Franchi Fonte y Lugo (La Orotava, 1670-1751) era poseedor del cuarto mayorazgo fundado por sus padres y está considerado el primero en la línea menor de los Franchi, esto es, la de los marqueses de la Candia y El Sauzal. Todos ellos eran copatronos del convento de San Agustín (fig. 5).

El 31 de mayo de ese año de 1730, el notario Alfonso y el vicario Bucaille accedieron a entregarle los documentos a Cristóbal de Franchi, pero éste los retuvo en su casa más días de los permitidos. Por esta razón la abadesa lo acusó de rebeldía y pidió que se le exigiera su devolución. El notario y el vicario notificaron al susodicho, bajo pena de excomunión, la obligación de devolverlos y éste lo hizo, pero alegando ciertos derechos que según su criterio tenía. En su escrito de alegación, Cristóbal de Franchi ofrece varios datos que ayudan a completar la imagen del retablo:

${ }^{14}$ Fue capitán de infantería, regidor perpetuo de Tenerife, alcaide y castellano del castillo de San Felipe del Puerto de la Cruz, alguacil mayor del Santo Oficio de la Inquisición, patrono de la capilla de los Santos Reyes de la iglesia de la Concepción y de la ermita de su familia, en La Orotava. Véase Hernández Béthencourt, Francisco (1878): Nobiliario y blasón de Canarias, tomo I. Santa Cruz de Tenerife: Imprenta Isleña, p. 315 y ss. 


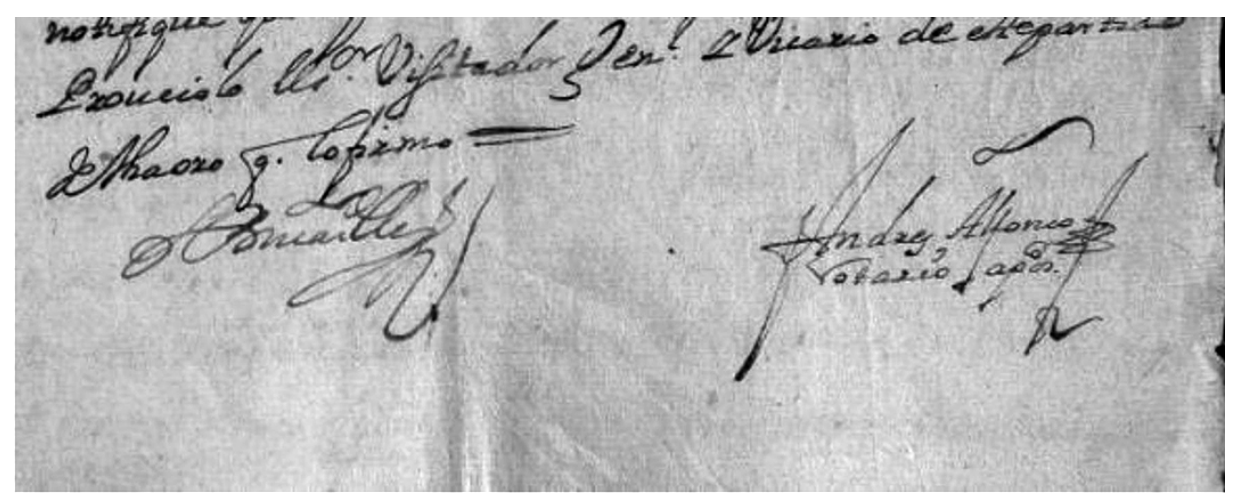

Fig. 5. Firmas de Martín Bucaille y Andrés Alfonso en los autos de 1730.

Don Cristobal de Franquis Vesino de esta Villa [...] paresco ante Vuestra merced en los autos intentados por parte del Conbento de relixiosas de Santa Clara desta Villa sobre el aseo y adorno de un altar en que se me an intimado los requerimientos hechos y Vuestra merced se a de servir declarar en caso necesario no deverme parar perjuicio el que se debe tapear dexando libre el sitio para el asiento a cuio fin se dio desde la fundacion. Lo uno porque sin la interbencion y concurso de todos los herederos interesados en dicho asiento y dacta no puede prebalecer lo hecho por uno que le moveria su devocion y empeńos dexando perjudicados a los demas sin lugar para el vanco que antes avia puesto ni asiento para las Señoras de la familia, aviendose estrechado de modo que con travaxo pasa y sube al pulpito el Predicador. Y lo otro sin perjuicio de lo antesedente (sobre que formo articulo de que pido pronunciamiento Con protesta de la nulidad) que aunque debiese mantenerse dicho altar debieran Contribuir todos los herederos sin que esté Yo Constituido en mas que en la prorrata o ha ser unico dueño de dicho altar y asiento en caso que Yo solo costease los aseos de él debiendo estimarse a Don Joan Domingo de franquis el allanamiento que hase pues sin tener derecho lexitimo ni cuidar de los patronatos antiguos de su Casa pues se halla la hermita de la Gloriosa Santa Catalina amenasando grave peligro, le conduse la devocion de dicho Combento a estar pronto a contribuir por tanto=

A Vuestra merced suplico se sirva proveer en todo como llevo pedido Justicia Costas Juro y protesto lo necesario ${ }^{15}$.

Por un lado, parece claro que las intenciones de Cristóbal de Franchi eran quedarse con la titularidad del altar si solamente él contribuía, alegando que su sobrino Juan Domingo, heredero principal de la casa Franchi, no ejercía bien su papel ni tendría derecho legítimo al uso del sitio. Al margen de las desavenencias

15 AHN, 1798-1. Autos... Documentos fechados entre 1730 y 1731. 


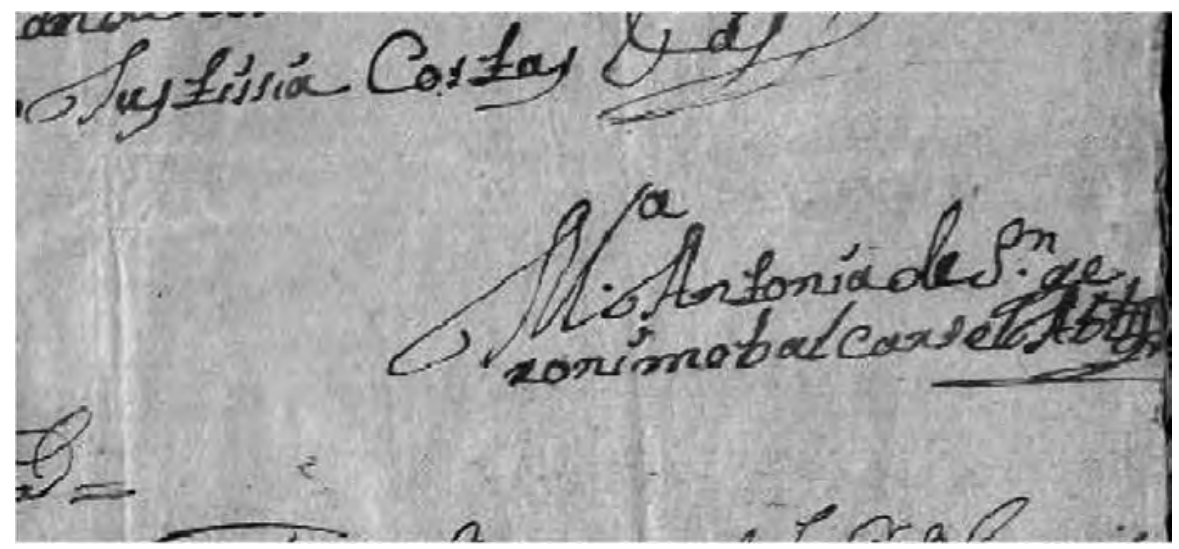

Fig. 6. Firma de la abadesa María Antonia de san Jerónimo Valcárcel en los autos de 1730.

familiares que trasluce el documento, es interesante la cuestión del espacio entre el retablo y el púlpito y la mención a los cambios sufridos en el mismo. En este sentido resulta imprescindible remitirse a otra serie de documentación generada a raíz de la alegación de Cristóbal de Franchi, que por otro lado fue claramente desestimada (fig. 6).

Como hemos referido, el convento, pero en especial su iglesia, fue sometido a una profunda renovación al comenzar el siglo xviII. Puede decirse que fue casi una reconstrucción, pero en el templo volvieron a colocarse los retablos ya existentes, entre ellos el que nos ocupa. De ahí que Cristóbal de Franchi se queje de cómo quedaba tan cerca del púlpito y haga alusión al «vanco que antes avia puesto». Como hemos dicho, su alegación fue rechazada y, es más, en la respuesta a la misma se expresaba también que el resto de herederos no habían dicho "cosa alguna que les libre de la expresada obligasion». De tal manera que fueron conminados a nombrar «peritos ynteligentes que estimen el balor de lo que nesesitare para dicho adorno y aseo y que lo que inportare lo declaren por ante el presente notario y que satisfagan y paguen prorrateadamente el cargo que a cada uno le pertenesiere». Se veían así los herederos de Franchi obligados a pagar el arreglo del retablo y posteriormente las costas de los autos.

Éste y otros documentos posteriores a los que nos referiremos a continuación incluyen información valiosa sobre el altar:

... porque el altar sobre que se litiga está formado después que nuebamente se formó el templo y iglesia de dicho monasterio con consentimiento y aprobasion de los padres comunes desde cuio transcurso lo an conserbado las otras partes con su resiproco consentimiento, en cuios terminos es intespestibo lo alegado por dicho don cristobal y de mantenerse dicho altar y para que tenga efeto obra tan piadosa y necesaria al culto que coresponde, a vuestra merced pido i suplico se sirba mandar se notifique a las otras partes nombren peritos con apersibimiento que se nombrarán 


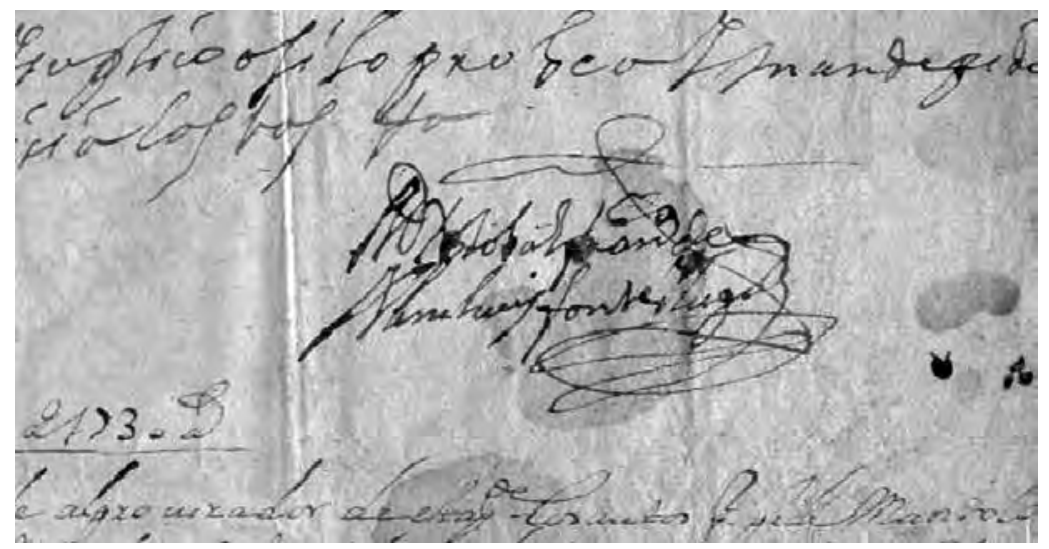

Fig. 7. Firma de Cristóbal de Franchi en los autos de 1730.

de ofisio y que cada uno haga su prorrata pues por la de dicho monasterio nonbro a Joseph García y a Juan de Flores que pido se aian por nombrados ${ }^{16}$ (fig. 7).

Se nombra entonces a Nicolás García, «maestro de lo fino de Carpintero", por parte del convento y a Juan Bautista de Flores por la otra parte ${ }^{17}$. Pocos días después se nombra también a José García, probablemente hermano del primero, también maestro carpintero. El 24 de ese mes comparecen ante el notario y dicen que «anbisto y reconosido el altar para que anssido nombrados y para que quede desente necesita de un retablo almodo del que tiene el altar de San Antonio que está en la misma Yglesia y tendrá de todo costo seis sientos reales». Y el día 31 lo hace Juan Bautista de Flores y dice que «senesesita gastar ochenta reales en dies baras de encaje para ellos a real= un atril y dos Candeleros que costarán veinte reales= $\mathrm{y}$ apoco costo se compone el frontal que tiene y es lo que puede decir». De la documentación se desprende que ninguno de los presupuestos fue aceptado por los herederos, por lo que Buenaventura Simón Ramírez, en representación del convento, y en respuesta a un escrito de Cristóbal Franchi en el que afirmaba que le correspondía la titularidad del retablo por haberse encargado del mismo y haber colocado en él la imagen del santo titular, afirmó que los peritos tuvieron que ser nombrados de oficio al no cumplir los herederos con lo dictado por el notario y les manda pagar los setecientos reales presupuestados. A pesar de que se les comunica

${ }^{16}$ AHN, 1798-1. Autos... Documento fechado en la segunda quincena de junio de 1730 e inserto en los autos.

17 Ann, 1798-1. Autos... Fueron nombrados el 17 de julio de 1730 ante el notario Andrés Alonso, con la presencia del alférez Antonio García Dorta y Lucas Delgado. 
la resolución del notario y el vicario, tanto Juan Domingo como Cristóbal Franchi se reafirmaron en febrero de 1731 sobre lo que ya habían expuesto y ratificaron sus respectivos escritos.

Finalmente, el 30 de julio de 1731 se dictó un auto en el que el licenciado Martín Bucaille Manrique de Lara, abogado de los Reales Consejos y beneficiado de la parroquia, examinador sinodal del obispado, visitador general y vicario del partido de Taoro, habiendo visto los autos mandó notificar a Cristóbal Francisco de Franchi y a Juan Domingo de Franchi, en un plazo de ocho días, para que "pomgan con toda decencia el altar q en ellos se refiere para que se pueda Celebrar el santo sacrificio dela misa Con apersevimiento que pasado dho termino sin haverlo hecho se dará la providensia q corresponde para quese ejecute» ${ }^{18}$.

Tras esta última notificación, debió llegarse a algún tipo de acuerdo o, al menos, los citados aceptaron lo dictaminado por el vicario y la tasación hecha por el convento. Esta circunstancia se desprende del propio documento, ya que parece acabar ahí, de lo que deducimos que finalmente se adecentó el altar, pues de lo contrario los autos hubiesen continuado. Además, como veremos a continuación, el retablo se mantuvo en el mismo emplazamiento hasta la demolición del convento.

\section{EL RETABLO DE LOS FRANCHI}

Es un hecho incuestionable el importante desarrollo arquitectónico del convento de San José de La Orotava y el valor de sus bienes muebles, la mayoría dispersados después de 1870 . Y, aunque en la documentación se dan datos acerca del retablo, no podemos afirmar con rotundidad a quién estaba dedicado. Pero intentaremos aportar la suficiente claridad sobre las hipótesis que plantearemos y a las que dedicamos este último apartado.

A comienzos del mes de octubre de 1868 el Ayuntamiento de La Orotava decidió dar por disuelto el convento y cerrarlo definitivamente. Con esta decisión, amparada bajo la Revolución llamada La Gloriosa y que acabó con el reinado de Isabel II, el consistorio quería ocupar el inmenso solar del monasterio y construir en él un nuevo ayuntamiento. Las obras de demolición empezarían a mediados de 1869, ya que el ministro de la Gobernación aprobó la misma en mayo de ese año y de aquel espacio saldrían las nuevas casas consistoriales y la Hijuela del Botánico ${ }^{19}$. Pero previamente al desmantelamiento del viejo convento, se realizaron los correspondientes inventarios. Y así, el 13 de octubre de 1868 se realizó el de alhajas y enseres, bajo la tutela del alcalde Tomás Román, el arcipreste José Borges, el capellán

${ }^{18}$ El 11 de septiembre se notificó a Juan Domingo de Franchi y el 16 de octubre a Cristóbal de Franchi.

${ }^{19}$ Lo estudiamos en Rodríguez Bravo, Jesús (2020): La Hijuela del Botánico de La Orotava: historia y naturaleza. La Orotava: LeCanarien ediciones. 


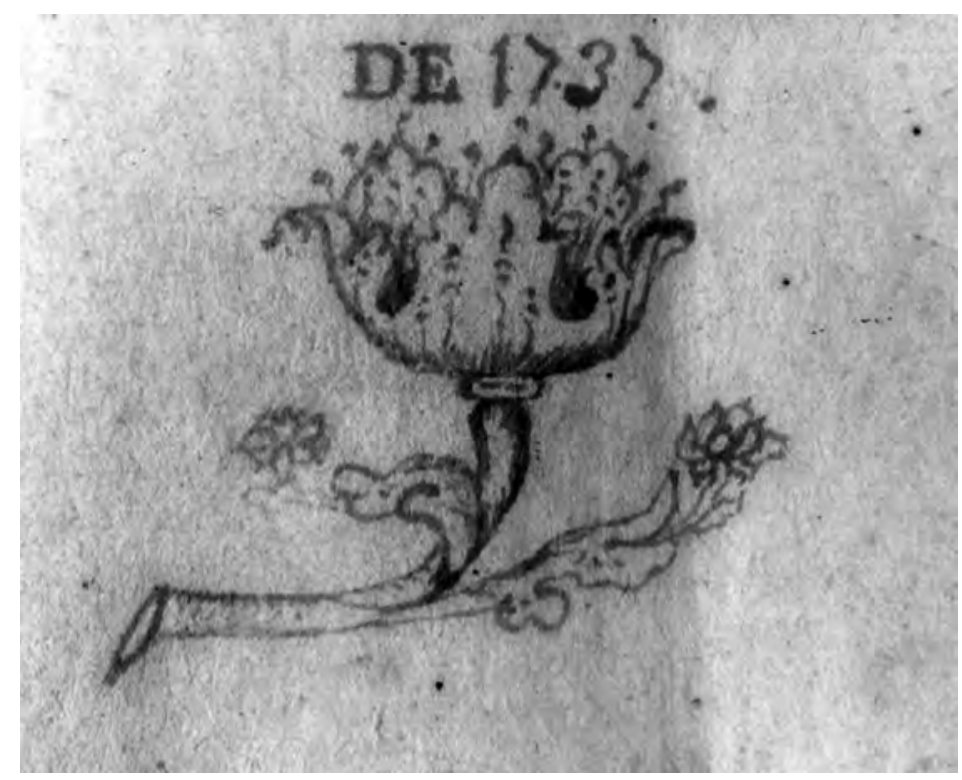

Fig. 8. Detalle en uno de los protocolos del convento en 1737.

del convento Antonio Delgado y Delgado y el notario José Gobea y Arbelo ${ }^{20}$. En él se anotaron los retablos hallados en la iglesia, entre ellos uno "con un nicho con San Rafael con un pescado y sombrero de madera», colocado junto al púlpito. Esta ubicación y un dato extraído de un escrito de Cristóbal de Franchi, incluido en los autos de 1730, nos llevan a afirmar que este retablo del arcángel san Rafael es el que perteneció a la familia Franchi y fue objeto de la disputa con las monjas. Ese dato se refiere a una afirmación del citado sobre que a él le debe corresponder el dominio sobre el altar, ya que se ha ocupado del mismo «desde que coloqué el Santo» ${ }^{21}$. Ningún otro retablo de la iglesia inventariado y situado junto al púlpito se corresponde con una advocación masculina, aunque sí que se nombra un retablo dedicado a san Nicolás, pero por su ubicación no parece corresponderse con el de los Franchi. Por lo tanto, es una posibilidad que el retablo al que hemos venido haciendo referencia estuviese dedicado a esta advocación. No obstante, hay que aclarar que este arcángel no es frecuente históricamente entre esta familia (fig. 8).

20 Archivo Municipal de La Orotava (en adelante AMLO), 1868. Ynventario de las alhajas y enceres que existian en el Convento Clariso de esta Villa.

${ }^{21}$ AHN, 1798-1. Autos... Documento fechado alrededor de enero de 1731 e inserto en los autos. 
Dada la dispersión a la que se vieron sometidas muchas de las obras de arte que albergaba el convento, resulta difícil determinar a dónde fue a parar el retablo, si es que sobrevivió al derribo. Aunque una hipótesis podría ser que acabase en la parroquia de Nuestra Señora del Rosario de La Perdoma, en la misma población, ya que la imagen de san Rafael que se conserva en dicha iglesia es la del titular de ese retablo. ¿Llegaría el retablo junto a la imagen? No lo podemos afirmar, aunque sí se sabe que en ese templo se depositaron varios lienzos e imágenes procedentes del convento clariso. Además, sabemos que en enero de 1882 existía en esta iglesia un retablo dedicado al arcángel san Rafael, además de un cuadro con la misma advocación ${ }^{22}$, pero en la reforma sufrida a partir de 1946 se suprimieron muchos de los bienes muebles.

Por la descripción hecha en el inventario de 1836, en la que se especifica que tiene un «sombrero de madera», es evidente que se trata de la escultura que estaba en la iglesia del convento. Pero no es posible afirmar que se trate de la misma que colocaron los Franchi en su retablo. Esta obra, muy poco estudiada hasta el momento, es una pieza interesante estilísticamente y digna de un mayor análisis. Por su porte, tratamiento de la indumentaria y trabajo del rostro correspondería a una obra del siglo XVIII, si bien es cierto que la ampulosa capa de telas encoladas puede ser un añadido posterior. De tratarse del titular del retablo que analizamos, sería una escultura de hacia 1730 o ligeramente anterior y encargada por Cristóbal de Franchi, tal vez en sustitución de otra que presidiera el altar desde el siglo Xvir. La figura presenta un ligero movimiento, enfatizado por la colocación delantera del pie derecho, la posición de los brazos y el suave ladeado de la cabeza. Esta postura la acercaría a la iconografía de otros arcángeles, especialmente a san Miguel, que tanto se difundió en Canarias en el marco de la plástica. Concuerda también con obras de filiación andaluza, sobre todo granadina, datadas en el siglo XviII, tanto por la composición como por el tratamiento de la policromía, en el ámbito de la escultura y de la estampa calcográfica. El atuendo de peregrino responde al gusto dieciochesco, en especial los botines altos y la amplia capa. En su mano izquierda porta el callao con el pan o la calabaza tan típico de su iconografía y en la derecha el pescado, muy propio de su representación, aunque aquí parece exceder en tamańo en relación con la escultura. Ambos elementos se asocian al pasaje del Libro de Tobías. Llama la atención el sombrero, citado en los inventarios como una característica particular de la imagen, y que no es frecuente en su representación, ya que su cabeza suele estar ceñida por una diadema de significado celestial. Un análisis estilístico de esta obra nos acerca a escultores canarios de ese período, especialmente entra dentro de los postulados del tinerfeño Sebastián Fernández Méndez «el joven» ${ }^{23}$ (figs. 9, 10 y 11), por lo que podría adscribirse a su gubia.

22 Rodríguez Mesa, Manuel (1979): En el pago de Higa, donde llaman La Perdoma. Santa Cruz de Tenerife, p. 95 y ss. También en el convento de San Lorenzo se rindió culto al mismo santo, con imagen y retablo.

${ }_{23}$ Agradezco las aportaciones al respecto de Clementina Calero Ruiz, Silvano Acosta Jordán y Adolfo Padrón Rodríguez. 

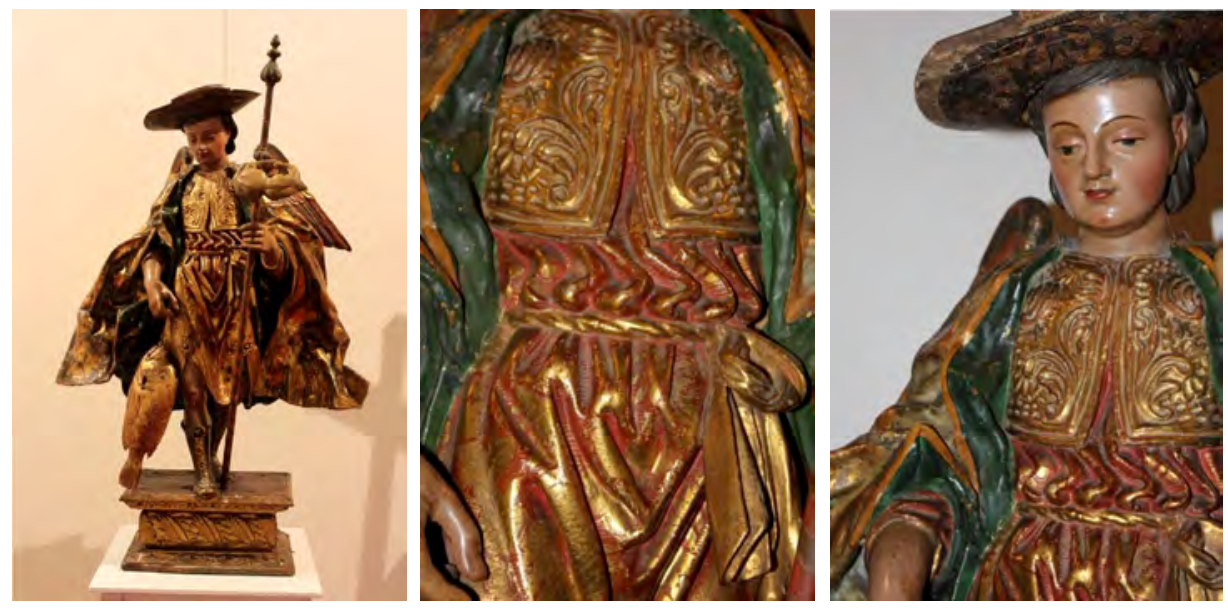

Figs. 9, 10 y 11. Arcángel san Rafael, siglo Xviır. Parroquia de Nuestra Señora del Rosario, La Perdoma, La Orotava. Fotos de Adolfo Padrón Rodríguez.

La advocación al arcángel debió tener cierta consideración, ya que en el propio convento de San José hubo dos lienzos representándolo. Así se recoge en el inventario realizado en 1836 por la Real Academia de Bellas Artes de San Fernando de Madrid, a través de las comisiones provinciales nombradas al efecto de saber qué «archivos, biblioteca, pinturas y demás enseres de utilidad a los institutos de ciencias y artes» había en cada institución religiosa del país ${ }^{24}$. El primero se hallaba en el coro alto junto a otras dieciocho obras y el segundo en el coro bajo junto a otros ocho cuadros $^{25}$. En la iglesia de San Francisco de La Orotava también existe una escultura del arcángel con una iconografía muy similar, de autor anónimo y llegada desde Cádiz en 1804, pero en este caso se vincula al carácter hospitalario del edificio.

Este retablo de san Rafael no fue la única relación que los Franchi tuvieron con el convento clariso. También estuvieron vinculados a una de sus cofradías más significativas, la del Dulce Nombre de Jesús, fundada alrededor de 1631 y cuya imagen titular tuvo una considerable devoción y había sido traída al monasterio por las propias monjas ${ }^{26}$. Esta imagen tenía una corona sobredorada que Guillén Home Franchi y Betancurt «mandó de yndias» en 1723 y cuyo cuidado corría de parte

24 Real Academia de Bellas Artes de San Fernando, Comisiones provinciales de monumentos histórico-artísticos, 2-46-1, Convento de monjas claras de la Villa de La Orotava, 16 de septiembre de 1836 .

${ }^{25}$ El inventario está firmado por Pedro Pascacio Perdigón, Domingo Currás, Guillermo Tomás Cullen, Fernando Llarena y la abadesa sor María de san Agustín Padrón.

${ }^{26}$ AHPT, Conventos, 2929. Libro de escrituras de la cofradía del santo nombre de Jesús. 


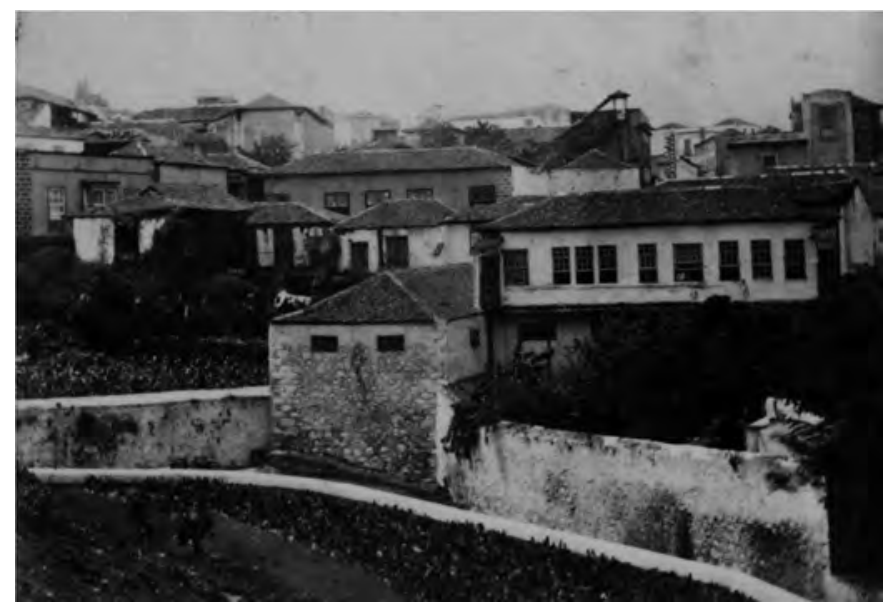

Fig. 12. La Orotava hacia 1869. Juan González Méndez. Puede apreciarse la base del ajimez y las cubiertas de la iglesia del convento en el momento de su desmantelamiento. Fuente: FEDAC.

de sus hermanas María Bernarda de Santa Inés y Juana Agustina de San Salvador, monjas en el convento y mayordomas de la cofradía ${ }^{27}$. También el capitán y familiar del Santo Oficio Juan Francisco de Franchi Alfaro como «devoto de la Cofradía» hizo donación de un censo de veinte ducados a pagar por el zapatero Juan Pérez y su mujer Juana Francisca, a razón de once reales anuales, sobre una casa situada en la calle Alfaro y una vińa en el Rincón ${ }^{28}$ (fig. 12).

RECIBIDO: 6-3-2020; ACEPTADO: 11-6-2020

27 Ibidem, f. 5.

${ }^{28}$ Fechado el 19 de marzo de 1637. 
